\title{
1. REESTRUTURAÇÃO CURRICULAR DA LICENCIATURA EM GESTÃO E DESENVOLVIMENTO SOCIAL
}

Na sequência de recomendações de uma Comissão, nomeada pelo Magnífico Reitor e presidida pelo Prof. Doutor Manuel Braga da Cruz, foi aprovada, na sessão do Conselho Superior da Universidade Católica Portuguesa, de 03 de Junho de 1994, a reestruturação curricular da licenciatura em Gestão e Desenvolvimento Social (GDS).

As recomendações da Comissão acima referida incidiram no sentido de reforçar a componente de Gestão da licenciatura, mantendo a de Desenvolvimento Social, com reflexos nas condições de acesso ao curso e na organização da respectiva parte escolar.

O que significa que a licenciatura em Gestão e Desenvolvimento Social, prosseguindo objectivos inscritos na sua criação, "nomeadamente gerir os recursos humanos" e preparar para o exercício de funções "de agente qualificado de desenvolvimento", foi orientada, na presente reestruturação, por um modelo científico que se concretiza nas seguintes características (cf. o organigrama, p. 190):

- concentração das disciplinas básicas, principalmente das áreas de Métodos Quantitativos e de Economia, nos dois primeiros anos do curso;

- aumento da carga horária nessas disciplinas básicas, embora admitindo uma adequada distribuição da mesma por aulas teóricas, teórico-práticas e práticas;

- inclusão das disciplinas mais especializadas nos dois últimos anos da parte escolar do curso;

- equilíbrio entre as componentes de Gestão e Desenvolvimento Social, embora com reforço da primeira.

Este modelo pretende fornecer uma sólida formação de base, nos primeiros anos, e conferir, progressivamente, uma formação mais específica nos anos terminais.

É acentuada a componente de Gestão e justificada, neste âmbito, a inclusão de novas disciplinas, como Política de Gestão e Negócio Internacional. Adicional- 


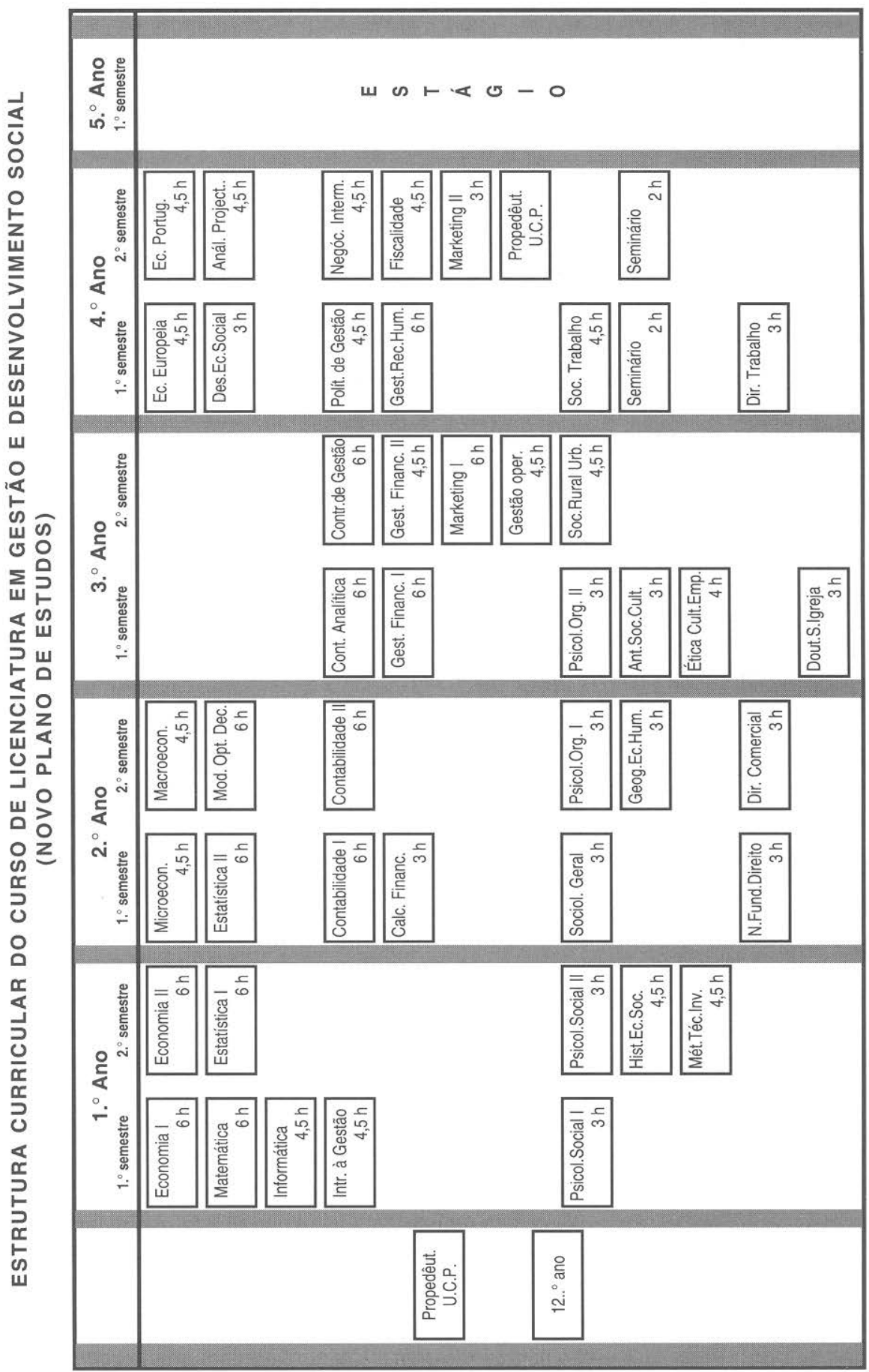


mente, as disciplinas de Marketing I e II, Gestão das Operações e Fiscalidade passarão a ser obrigatórias.

A observação do organigrama revela que a parte escolar da licenciatura foi concentrada em quatro anos, permitindo reservar o $5 .^{\circ}$ ano $\left(1 .^{\circ}\right.$ semestre) para a realização do Estágio.

Esta medida visa libertar o último ano do curso (embora com a duração de um semestre) do Seminário (que é antecipado para o $4 .^{\circ}$ ano) e das disciplinas que o actual plano de estudos contém, permitindo, assim, uma concentração total nas actividades de Estágio.

Este, que vem sendo realizado, desde o ano lectivo de 1990/91, em organizações de diversa natureza - empresas, bancos, autarquias, associações industriais e comerciais, instituições particulares de solidariedade social —, continuará a ter um papel relevante em termos de confrontar os nossos futuros licenciados com a realidade socioprofissional em que irão desempenhar a sua actividade.

Permito-me, a este respeito, destacar os efeitos altamente positivos de um estágio como o da licenciatura em GDS, na medida em que permite uma formação mais completa e adequada ao exercício profissional e facilita a entrada no mercado de trabalho dos recém-licenciados. Os Relatórios de Estágio dos nossos licenciados testemunham bem o esforço desenvolvido e a preparação conferida por essa importante componente do currículo.

Como já acontecia com o plano de estudos anterior, o grau de licenciados em Gestão e Desenvolvimento Social será conferido aos alunos após aprovação em todas as disciplinas que integram o plano de estudos, no Seminário e, também, depois de realizado o Estágio e apresentado e discutido o respectivo Relatório. Para efeitos do cálculo da informação final de licenciatura, todas as disciplinas terão a ponderação de um, o Seminário de dois e o Estágio de três. Os critérios e condições de acesso ao curso constituíram um dos aspectos da reestruturação curricular que implicou uma modificação substancial, que cumpre justificar.

A modificação traduz-se na obrigatoriedade de a Matemática passar a ser disciplina específica, deixando a Filosofia de o ser.

Esta decisão tem por fundamento o papel que a Matemática desempenha, como pré-requisito essencial, para a frequência de disciplinas nessa área científica (Matemática e Modelos de Optimização e Decisão, por exemplo), bem como das de Cálculo Financeiro e Gestão das Operações. Trata-se de um instrumento essencial para um adequado domínio de matérias em que a componente de cálculo é essencial.

Em conformidade com o critério acima definido, a candidatura ao Ano Propedêutico só poderá ser apresentada pelos alunos que possuam o $11 .^{\circ}$ ano de escolaridade (ou possam completá-lo até final do ano lectivo em que ocorrer a candidatura), desde que tenham feito a disciplina de Matemática, independentemente da componente de formação vocacional. 
As provas de exames de admissão são as seguintes:

- Prova de Aptidão Cultural;

- Prova específica de Matemática (duas, preferindo-se, para efeitos de classificação, aquela em que o candidato obtenha classificação mais elevada).

Por sua vez, para a admissão ao $1 .^{\circ}$ Ano, é exigido aos candidatos que possuam o $12 .^{\circ}$ ano de escolaridade em cursos em que a Matemática seja disciplina de base e que tenham realizado a prova de aferição.

As provas de exame de admissão ao $1 .^{\circ}$ ano são, também, a de Aptidão Cultural e a específica de Matemática (duas, observando-se o critério de preferência pela melhor das notas obtidas).

Quando se efectuam reestruturações curriculares, podem adoptar-se diversos critérios, nomeadamente aplicar a reestruturação apenas aos alunos que se vão matricular no $1 .^{\circ}$ Ano, ou, em alternativa, prever a possibilidade de transição dos alunos dos outros anos (designadamente dos que, no ano lectivo em que a reestruturação se efectuou, se encontram a frequentar o $1 .^{\circ} \mathrm{e} \mathrm{o} 2 .^{\circ}$ anos do curso).

Na presente reestruturação, optou-se pela segunda hipótese, embora de uma forma limitada. O que significa que, sem prejuízo de os actuais alunos do $1 .^{\circ} \mathrm{e}$ do $2 .^{\circ}$ anos permanecerem até ao fim do curso no plano de estudos que iniciaram, lhes é facultada a possibilidade de transitarem para o novo plano de estudos. Neste sentido, os alunos do $1 .^{\circ}$ e $2 .^{\circ}$ anos puderam optar, já no ano lectivo de 1994/95, pelo novo currículo ou pelo anterior.

A implementação da reestruturação curricular tem exigido um notável esforço do I.U.D.P.S., atendendo à entrada em funcionamento do novo plano de estudos no $1 .^{\circ}$ ano da licenciatura, bem como ao funcionamento de um regime transitório para os alunos do $2 .^{\circ}$ e $3 .^{\circ}$ anos que optaram pelo currículo reestruturado.

\section{CURSO DE PÓS-GRADUAÇÃO EM GESTÃO DE EMPRESAS}

O Instituto Universitário de Desenvolvimento e Promoção Social e a Faculdade de Ciências Económicas e Empresariais promoveram o lançamento, no decorrente ano lectivo, do Curso de Pós-graduação em Gestão de Empresas.

Tendo como objectivos primaciais permitir a abertura de novas perspectivas e adquirir os instrumentos indispensáveis ao desenvolvimento de soluções concretas para problemas reais da gestão, o Curso de Pós-graduação em Gestão de 192 Empresas iniciou-se, consoante o previsto, em Outubro do decorrente ano lectivo, 